\title{
Enhanced Stereocontrol in Disyndiotactic-specific Group Transfer Polymerization of Methyl Crotonate-Stereochemical Evidence of Group Transfer
}

\author{
Koichi Ute, Toshiyuki TARAO, and Tatsuki KitAYAmA ${ }^{\dagger}$ \\ Department of Chemistry, Graduate School of Engineering Science, Osaka University, \\ 1-3 Machikaneyama, Toyonaka 560-8531, Japan
}

(Received February 10, 2005; Accepted April 30, 2005; Published August 15, 2005)

\begin{abstract}
Group transfer polymerization (GTP) of methyl crotonate was examined by using a ketene silyl acetal with tert-butyldimethylsilyl group in the presence of $\mathrm{HgI}_{2}$ and tert-butyldimethylsilyl iodide as a catalyst and a co-catalyst, respectively. Under optimized conditions, the GTP produced disyndiotactic polymers with narrow molecular weight distribution in quantitative yields. The trialkylsilyl group in the initiator components was found to exert control over the stereochemical process of the GTP; the bulky tert-butyldimethylsilyl group leads to the highest disyndiotacticity. The results provide a direct evidence for the transferring silyl group to be involved in the propagation steps in the GTP. [DOI 10.1295/polymj.37.578]

KEY WORDS Ditacticity / Stereoregularity / Methyl Crotonate / Ketene Silyl Acetal / 1-Methoxy-1-(tert-butyldimethylsiloxy)-1-propene /
\end{abstract}

Group transfer polymerization (GTP), disclosed in early 1980's by Webster, ${ }^{1}$ is one of the versatile living polymerizations for acrylic monomers. The GTP involves ketene silyl acetals as initiators and nucleophilic or Lewis acidic catalysts and has been claimed to proceed through migration or transfer of the silyl group to maintain ketene silyl acetal units at the propagating polymer chain-ends during the polymerization. The proposed mechanism, so-called "associative mechanism", assumes active intermediates carrying the silyl group. ${ }^{1-3}$ On the other hand, a dissociative mechanism has also been proposed, which regards the active intermediate as an enolate as in the case of classical anionic polymerizations. ${ }^{4-6}$

The above mechanistical argument has urged several researchers to examine the stereochemistry of GTP with the expectation of any specific effects of the ketene silyl acetal ends on the stereochemical aspect of the propagation reaction, if the associative mechanism dominates the GTP. For example, Müller and Sticker reported that syndiotacticity of poly(methyl methacrylate) (PMMA) obtained by the GTP using nucleophilic catalyst was slightly lower than that of PMMA obtained by radical polymerization. ${ }^{7}$ Mechanism and stereospecificity of the GTP were also discussed for cyclization polymerization of a binaphthyl dimethacrylate by Nakano and Sogah based on the results that the isotacticity of the polymer obtained by the GTP was higher (34\%) than that that of the polymer obtained by radical polymerization. ${ }^{8}$ GTP giving stereoregular polymers was reported for the polymerization of triphenylmethyl methacrylate using a nucleophilic catalyst $(m m=91 \%) .{ }^{9}$ Judging from the fact that radical and anionic polymerizations of this monomer also give the isotactic polymers,${ }^{10}$ however, the result is hardly regarded as "stereocontrol by GTP".

We have reported the GTP of methyl crotonate, a structural isomer of methyl methacrylate, using ketene silyl acetals (1) and (2) (Scheme 1), in the presence of $\mathrm{HgI}_{2}$ and trialkylsilyl iodides $\left(\mathrm{R}_{3} \mathrm{SiI}\right)$ as catalysts. ${ }^{11}$ Later, the GTP of other alkyl crotonates (alkyl = ethyl, $n$-propyl, isopropyl, or $n$-butyl) was also found successful. ${ }^{12}$ The combined catalyts $\mathrm{HgI}_{2} / \mathrm{R}_{3} \mathrm{SiI}$ has been known effective for the GTP of acrylates. ${ }^{13}$ The predominant stereochemical structure of poly(methyl crotonate) (PMC) thus formed was found disyndiotactic (Scheme 2) by X-ray analysis of the oligomers and NMR spectroscopy of the polymers and oligomers. ${ }^{14}$

${ }^{1} \mathrm{H}$ NMR spectra indidated that the polymer obtained with 1-methoxy-1-(triethylsiloxy)-2-methyl1-propene (2) has higher stereoregularity than that with 1-methoxy-1-(trimethylsiloxy)-2-methyl-1-propene (1). The results prompted us to examine the effect of trialkylsilyl group in the GTP initiator on the stereocontrol of the GTP of the crotonate. In this paper, we chose tert-butyldimethylsilyl group as a bulkier silyl group in the initiator, 1-methoxy-1-(tertbutyldimethylsiloxy)-1-propene $(3)^{15} \quad$ (Scheme 1), which formed a disyndiotactic PMC with much higher stereoregularity than those obtained with (1) and (2). Accordingly, the stereocontolled GTP was realized at a high level through the rational initiator design.

${ }^{\dagger}$ To whom correspondence should be addressed (Tel: +81-6-6850-6230, Fax: +81-6-6841-0104, E-mail: kitayama@chem.es.osaka-u.ac.jp). 

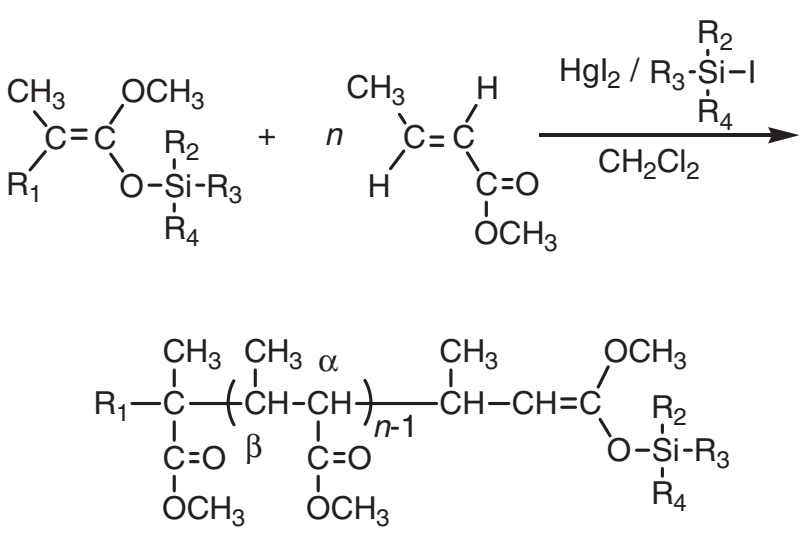

$$
\begin{aligned}
& \text { 1: } R_{1}=R_{2}=R_{3}=R_{4}=M e \\
& \text { 2: } R_{1}=M e, R_{2}=R_{3}=R_{4}=E t \\
& \text { 3: } R_{1}=H, R_{2}=R_{3}=M e, R_{4}=\text { tert-Bu }
\end{aligned}
$$

Scheme 1. Group transfer polymerization of methyl crotonate.

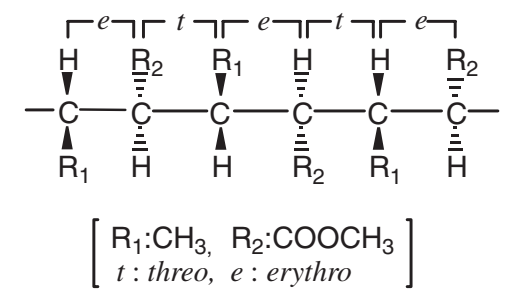

Scheme 2. Disyndiotactic poly(methyl crotonate).

\section{EXPERIMENTAL}

\section{Synthesis of $(3)^{16-21}$}

1-Methoxy-1-(tert-butyldimethylsiloxy)-1-propene (3) was prepared by the following procedure; tertbutyldimethylsilyl trifluoromethanesulfonate $(20 \mathrm{~g}$, $0.076 \mathrm{~mol}$ ), prepared from tert-butyldimethylsilyl chloride and trifluoromethanesulfonic acid, was allowed to react with methyl propionate $(33.4 \mathrm{~g}, 0.379$ $\mathrm{mol})$ in the presence of triethylamine $(38.4 \mathrm{~g}, 0.379$ mol) in diethyl ether $(90 \mathrm{~mL})$ under a dry nitrogen atmosphere for $20 \mathrm{~h}$. After the solvent was removed by evaporation, (3) was obtained by distilling the residue (b.p. $49.0-49.8^{\circ} \mathrm{C} / 2.2 \mathrm{mmHg}$ ); yield $3.0 \mathrm{~g}$ (19.3\%).

\section{Synthesis of tert-butyldimethylsilyl iodide (TBSI $)^{22}$}

To a mixture of tert-butyldimethylsilane $(5.0 \mathrm{~g}$, $0.043 \mathrm{~mol})$ and methyl iodide (13.8 g, $0.069 \mathrm{~mol})$, palladium chloride $(24 \mathrm{mg}, 0.14 \mathrm{mmol})$ was added, and the mixture was stirred at room temperature for $24 \mathrm{~h}$. Excess methyl iodide was distilled off, and the residue was recrystallized from diethyl ether to give $9.3 \mathrm{~g}$ (90\% yield) of TBSI.

\section{Polymerization Procedure}

Polymerization of methyl crotonate was carried out by a syringe technique under nitrogen in glass tubes equipped with three-way stopcock. A typical example is given below. To a stirred mixture of methyl crotonate $(10 \mathrm{mmol}), \mathrm{HgI}_{2}(0.016 \mathrm{mmol})$ and TBSI $(0.048$ $\mathrm{mmol})$ in $\mathrm{CH}_{2} \mathrm{Cl}_{2}(0.6 \mathrm{~mL})$, a solution of ketene silyl acetal (3) in $\mathrm{CH}_{2} \mathrm{Cl}_{2}(0.2 \mathrm{mmol}$ in $3.6 \mathrm{~mL})$ was added to initiate the polymerization reaction. After a predetermined period of the reaction, $0.2 \mathrm{~mL}$ of trifluoroacetic acid was added to the mixture, and then the volatile components were removed by evaporation under reduced pressure. The residue was dissolved in a mixture of $\left(\mathrm{CF}_{3}\right)_{2} \mathrm{CHOH}$ and acetone, and the solution was poured into a large amount of $\mathrm{CH}_{3} \mathrm{OH} /$ $\mathrm{H}_{2} \mathrm{O}(1 / 1, \mathrm{v} / \mathrm{v})$. The precipitated polymer was collected by filtration, washed several times with $\mathrm{CH}_{3} \mathrm{OH}$ / $\mathrm{H}_{2} \mathrm{O}$, and dried at $40^{\circ} \mathrm{C}$ for $6 \mathrm{~h}$.

\section{Measurements}

Size exclusion chromatography (SEC) was performed on a JASCO PU-980 chromatograph equipped with Polymer Laboratories SEC columns PLgel Mixed-D $(7.5 \mathrm{~mm} \times 300 \mathrm{~mm} \times 2$, maximum porosity $4 \times 10^{5}$ ) and a JASCO RI-930 detector using $\mathrm{CHCl}_{3}$ as an eluent at $40^{\circ} \mathrm{C}$. Molecular weight was calibrated against standard PMMA samples (Shodex). NMR spectra were recorded on Varian Unity-Inova 750 and 500 spectrometers in $\left(\mathrm{CF}_{3}\right)_{3} \mathrm{CHOH} / \mathrm{C}_{6} \mathrm{D}_{6}(95 / 5$, $\mathrm{v} / \mathrm{v})$ at $55^{\circ} \mathrm{C}$ or in $\mathrm{CDCl}_{3}$ at $35^{\circ} \mathrm{C}$. The strong resonances due to $\left(\mathrm{CF}_{3}\right)_{3} \mathrm{CHOH}$ were suppressed by the WET method. ${ }^{23}$

\section{RESULTS AND DISCUSSION}

Polymerization of methyl crotonate was carried out with ketene silyl acetal (3) in the presence of $\mathrm{HgI}_{2}$ as a catalyst and TBSI as a co-catalyst in $\mathrm{CH}_{2} \mathrm{Cl}_{2}$. The ratio of $\mathrm{HgI}_{2}$ and TBSI employed is close to the optimized value for the previously reported GTP of methyl crotonate. ${ }^{11}$ The results are summarized in Table I. The polymerizations at 0 and $-20^{\circ} \mathrm{C}$ gave PMCs with fairly narrow molecular weight distribution (MWD) with the maximum yield, while the yield decreased and MWD became broader with decreasing polymerization temperature. The broader MWD of the polymers formed at lower temperatures could partly be ascribed to the fact that the polymer formed in the medium precipitated out below $-40^{\circ} \mathrm{C}$ during the polymerization. At $-78^{\circ} \mathrm{C}$, the yield hardly reached completeness even when the polymerization period was extended for $600 \mathrm{~h}(65 \%)$. The polymerization at $+20{ }^{\circ} \mathrm{C}$ resulted in a quite low yield (13\%), probably due to self-termination by cyclization and/or $O$-to- $C$ silyl isomerization of propagating chain-ends..$^{14,24,25}$ 


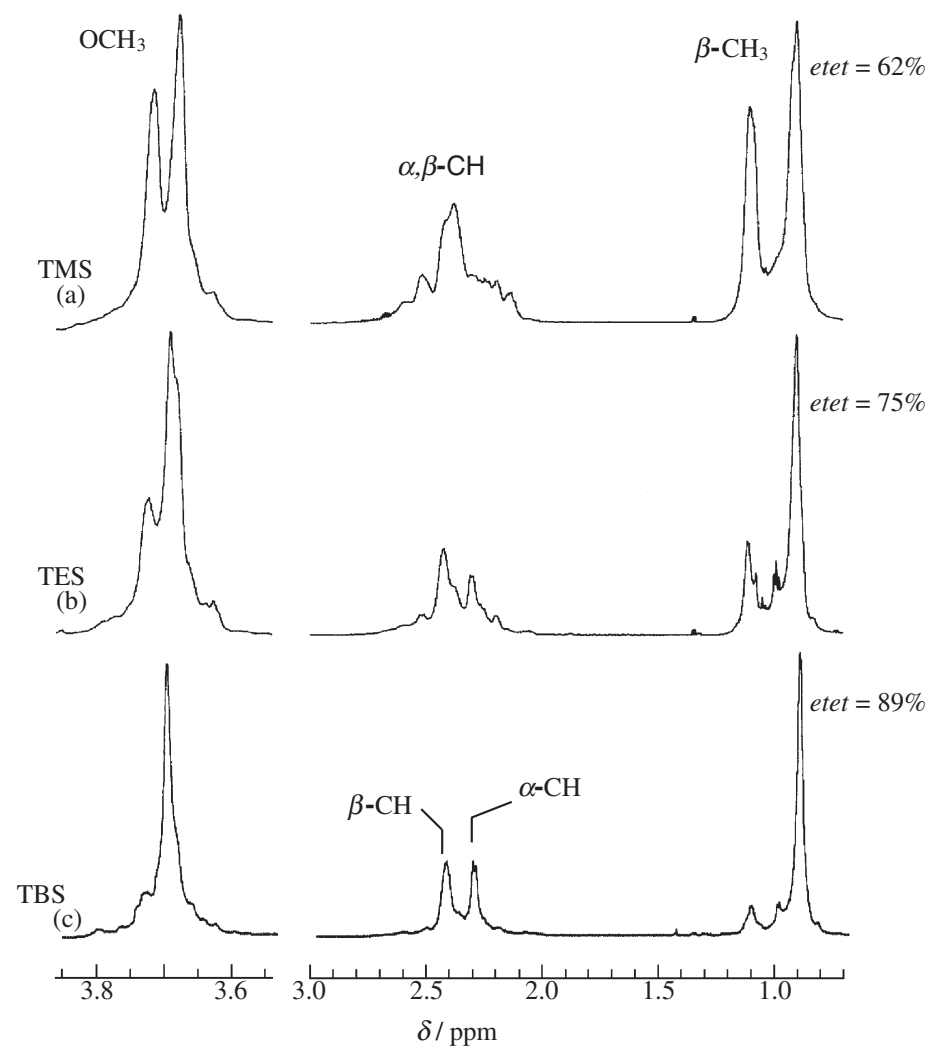

Figure 1. ${ }^{1} \mathrm{H}$ NMR spectra of PMCs prepared by the GTP with $\mathbf{3}$ (a), 2 (b) and $\mathbf{1}(\mathrm{c})\left(\left(\mathrm{CF}_{3}\right)_{2} \mathrm{CDOD} / \mathrm{C}_{6} \mathrm{D}_{6}(95 / 5 \mathrm{v} / \mathrm{v}), 55^{\circ} \mathrm{C}, 750 \mathrm{MHz}\right)$.

Table I. GTP of methyl crotonate with 1-methoxy-1-(tertbutyldimethylsiloxy)-2-propene (3) in the presence of $\mathrm{HgI}_{2}$ and TBSI in $\mathrm{CH}_{2} \mathrm{Cl}_{2}{ }^{\mathrm{a}}$

\begin{tabular}{|c|c|c|c|c|c|}
\hline Initiator & Temp & Time & Yield & $\bar{M}_{\mathrm{n}}{ }^{\mathrm{b}}$ & $\bar{M}_{\mathrm{s}} / \bar{M}_{\mathrm{b}}^{\mathrm{b}}$ \\
\hline $\mathrm{mmol}$ & ${ }^{\circ} \mathrm{C}$ & $\mathrm{h}$ & $\%$ & $10^{3}$ & \\
\hline 0.1 & 20 & 24 & 13 & 2.4 & 1.28 \\
\hline 0.1 & 0 & 24 & 65 & 9.0 & 1.26 \\
\hline 0.2 & 0 & 24 & 99 & 6.7 & 1.16 \\
\hline 0.2 & -20 & 24 & 99 & 7.1 & 1.15 \\
\hline 0.2 & -40 & 24 & 73 & 6.3 & 1.31 \\
\hline 0.2 & -60 & 24 & 47 & 2.2 & 1.44 \\
\hline 0.2 & -78 & 600 & 65 & 3.2 & 2.16 \\
\hline $0.1^{\mathrm{c}}$ & -20 & 168 & 83 & 32.4 & 1.35 \\
\hline
\end{tabular}

${ }^{\mathrm{a}}$ Monomer, $10 \mathrm{mmol}$; $\mathrm{HgI}_{2}, 0.016 \mathrm{mmol}$; TBSI, $0.048 \mathrm{mmol}$; $\mathrm{CH}_{2} \mathrm{Cl}_{2}, 4 \mathrm{~mL}$. ${ }^{\mathrm{b}} \mathrm{By}$ SEC. ${ }^{\mathrm{c}}$ Monomer, $20 \mathrm{mmol} ; \mathrm{HgI}_{2}, 0.032$ mmol; TBDMSI, $0.096 \mathrm{mmol} ; \mathrm{CH}_{2} \mathrm{Cl}_{2}, 8 \mathrm{~mL}([\mathrm{M}] /[\mathrm{I}]=200)$.

A similar temperature dependence has been observed for the GTP with (1) and (2). ${ }^{14}$

To obtain higher molecular weight PMC, the polymerization was conducted at $[\mathrm{M}]_{0} /[\text { initiator }]_{0}$ ratio of $200 \mathrm{~mol} \mathrm{~mol}^{-1}$ for $168 \mathrm{~h}$ at $-20^{\circ} \mathrm{C}$. The polymer was obtained in a high yield with the number-average molecular weight $\left(\bar{M}_{\mathrm{n}}\right)$ of $32 \times 10^{3}$, the value of which is the highest so far reported for PMC directly obtained by polymerizing methyl crotonate, while the GTP of other alkyl crotonates gives the polymers with $\bar{M}_{\text {n }}$ upto $90 \times 10^{3} \cdot{ }^{12}$
Figure 1 shows ${ }^{1} \mathrm{H}$ NMR spectrum of PMC obtained with 3 /TBSI at $-40{ }^{\circ} \mathrm{C}$ together with those of PMCs obtained with 1 /trimethylsilyl iodide (TMSI) and $\mathbf{2}$ /triethylsilyl iodide (TESI) at the same temperature. Peak assignments are shown in the figure according to our previous report. ${ }^{14} \beta-\mathrm{CH}_{3}$ proton signals split into two principal peak groups, whose relative intensities vary depending on the initiators used. Based on NMR data of pure disyndiotactic oligomers, the major peak at $0.90 \mathrm{ppm}$ has been assigned to disyndiotactic sequence or etet sequence (see Scheme 2), and the minor peak at $1.12 \mathrm{ppm}$ to a defect sequence, which will be discussed later. At the same time, $\mathrm{CH}$ and $\mathrm{OCH}_{3}$ signals of the former PMC are much simpler than those of the other two. Apparently, the PMC formed with 3/TBSI exhibits much higher stereoregularity or higher etet content than the other two PMCs; bulkier the silyl group of the initiator, higher the stereoregularity of the polymer. The results clearly indicate that the stereospecificity of the GTP of methyl crotonate is affected by the silyl group of the initiator, ${ }^{26}$ which presumably transfers in every propagation step to form the ketene silyl acetal end-group, as the original GTP concept ${ }^{1}$ anticipates, so as to exert influence on the stereochemical aspects of the propagation reaction.

Figure 2 shows ${ }^{1} \mathrm{H}$ NMR spectra of PMCs obtained with $\mathbf{3} /$ TBSI at different polymerization temperatures. Stereoregularity of the polymer, as judged from the 


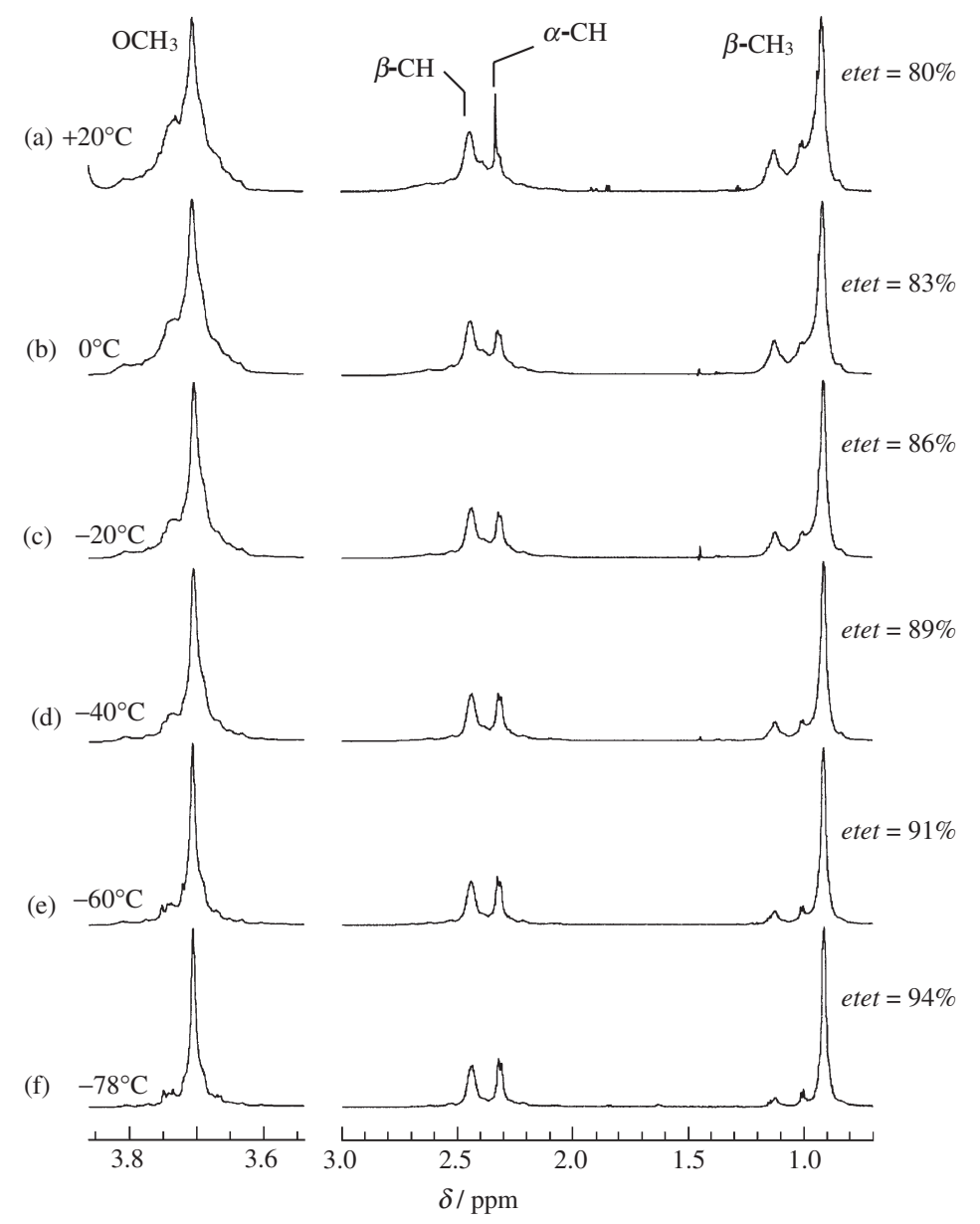

Figure 2. ${ }^{1} \mathrm{H}$ NMR spectra of PMCs prepared by the GTP with $3 / \mathrm{HgI}_{2} / \mathrm{TBSI}$ at $+20^{\circ} \mathrm{C}(\mathrm{a}), 0{ }^{\circ} \mathrm{C}(\mathrm{b}),-20^{\circ} \mathrm{C}(\mathrm{c}),-40^{\circ} \mathrm{C}(\mathrm{d}),-60^{\circ} \mathrm{C}$ (e) and $-78^{\circ} \mathrm{C}$ (f) $\left(\left(\mathrm{CF}_{3}\right)_{2} \mathrm{CDOD} / \mathrm{C}_{6} \mathrm{D}_{6}(95 / 5 \mathrm{v} / \mathrm{v}), 55^{\circ} \mathrm{C}, 750 \mathrm{MHz}\right)$.

Letters " $e$ " and " $t$ " in "etet" denote erythro and threo configurations of the neighboring substituents $\left(\mathrm{CH}_{3}\right.$ and $\left.\mathrm{COOR}\right)$ (see $\left.\mathrm{Scheme} 1\right)$.

relative intensity of the peak at $0.9 \mathrm{ppm}$ in the $\beta-\mathrm{CH}_{3}$ region, becomes gradually higher with decreasing polymerization temperature, and reached $94 \%$ at $-78^{\circ} \mathrm{C}$.

The highly disyndiotactic PMC still exhibits a $\beta-\mathrm{CH}_{3}$ signal at $1.12 \mathrm{ppm}$ as the minor component due to stereochemical defects in the chain. We have demonstrated from the stereochemical analysis of pure disyndiotactic oligomers, that the GTP proceeds in trans-opening of the double bond of the monomer, giving erythro configuration, and threo addition of the subsequent monomer addition to generate etet sequences. ${ }^{14}$ It should be noted that the configurational analysis of the given polymer does not afford such information but only the repetition of $e$ and $t$ configurations is recognizable, while the monomeric units in the oligomer can be identified from the initial to terminal ends.

If the stereochemical fault during the propagation process happens in an isolated manner, two types of defect sequences are generated within the enough long etet sequence; --tete e etete--- $[\mathrm{A}]$, and -- -tetett tete-- [B] (Scheme 3).
The sequence $[\mathrm{B}]$ is comprised of diheterotactic sequences, ett $t$ and $t$ te $t$, which are found in a diheterotactic PMC (Scheme 4) derived from poly(tertbutyl crotonate) prepared with diphenylmagnesium in toluene. ${ }^{27}$

Figure 3 illustrates ${ }^{1} \mathrm{H}$ NMR spectra of three types of stereoregular PMCs so far reported, disyndiotactic, threodiisotactic, and diheterotactic PMCs, together with that of atactic-like one. The chemical shifts of the $\beta$-methyl signals of the diheterotactic PMC (ett $t$; $0.93 \mathrm{ppm}$, t te $t ; 1.04 \mathrm{ppm}$ ) are different from that of the minor $\beta$-methyl signal (1.12 ppm) (see Figure 3). Thus the defect in the disyndiotactic PMC is not likely the type [B] but the type [A], the latter of which might be generated through the fault not in the mode of double-bond opening but in the direction of monomer addition.

\section{CONCLUSIONS}

The present work demonstrates that highly disyndiotactic PMC can be obtained by the GTP using 1methoxy-1-(tert-butyldimethylsiloxy)-1-propene (3), 
(A)Fault in the monomer addition

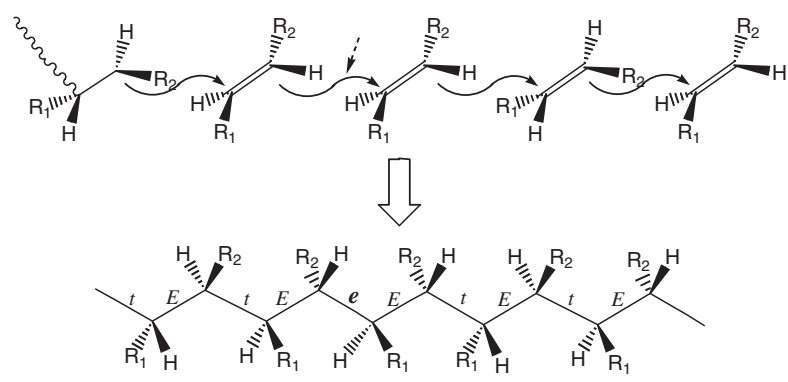

(B)Fault in the double-bond opening

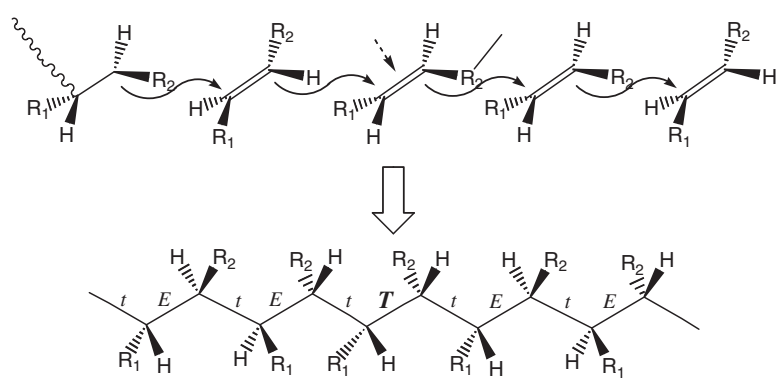

Scheme 3. Possible mechanisms of defect formation in the disyndiotactic sequence of PMC. Capital letters " $E$ " and " $T$ " are used to denote the relative configurations formed through the double-bond opening, while the lower-case letters indicate those formed through monomer addition process.

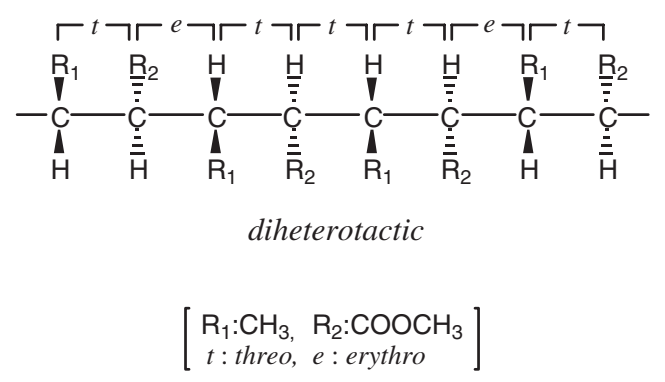

Scheme 4. Diheterotactic poly(methyl crotonate).

where stereoregularity of PMCs could be controlled most probably through the steric demand of the bulky $\mathrm{R}_{3} \mathrm{Si}$ - group of the initiator which transfers in every propagation step to stay at the ketene silyl acetal terminal, as the original GTP concept ${ }^{1}$ anticipates, so as to exert influence on the stereochemical process of the propagation reaction. Higher stereoregularity of the polymer also facilitates the stereochemical assignment of the minor configulational component in the polymer to be the sequence---etete e etet--, which in turn reveals the stereochemical fault during the propagation. In conclusion, high level of stereocontrol is now realized by the GTP process with rational design of the transferring group of the initiator.

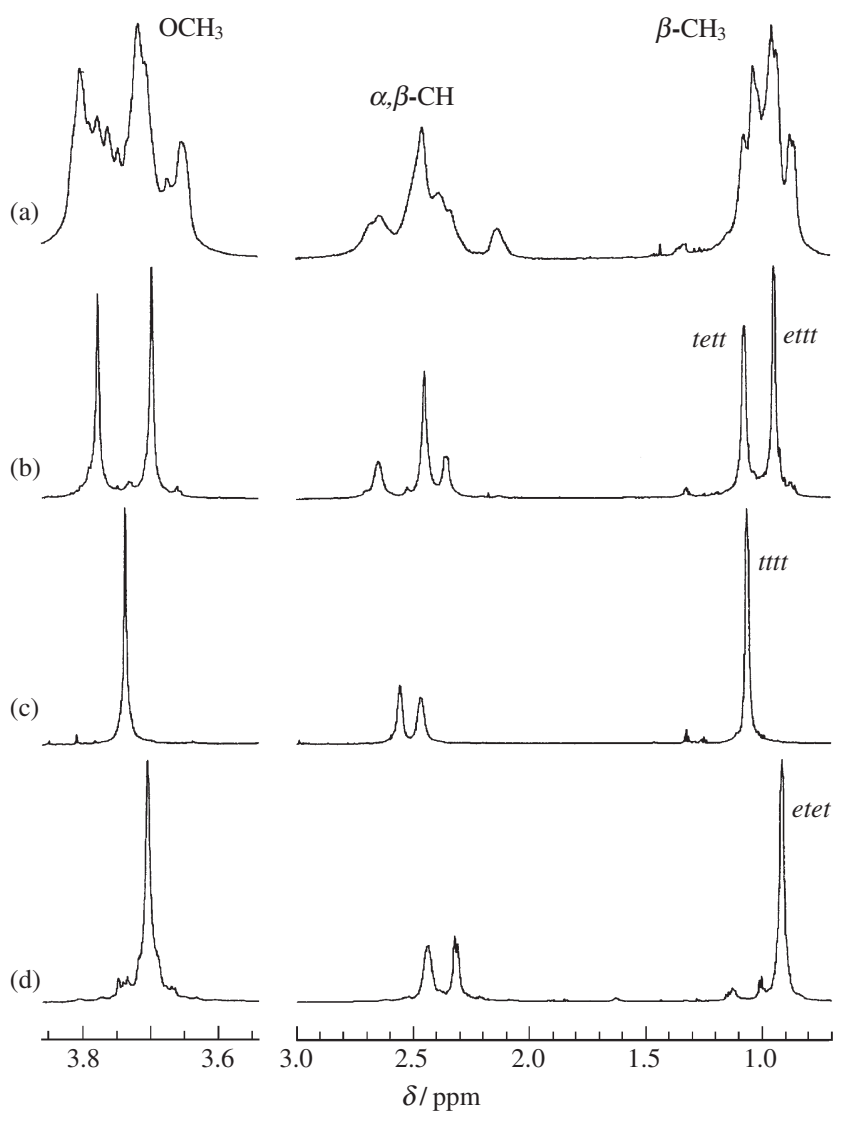

Figure 3. ${ }^{1} \mathrm{H}$ NMR spectra of atactic (a), diheterotactic (b), threodiisotactic (c), and disyndiotactic PMCs $\left(\left(\mathrm{CF}_{3}\right)_{2} \mathrm{CDOD} /\right.$ $\left.\mathrm{C}_{6} \mathrm{D}_{6}(95 / 5 \mathrm{v} / \mathrm{v}), 55^{\circ} \mathrm{C}, 750 \mathrm{MHz}\right)$.

\section{REFERENCES}

1. O. W. Webster, W. R. Hertler, D. Y. Sogah, W. B. Farnham, and T. V. Rajanbabu, J. Am. Chem. Soc., 105, 5706 (1983).

2. W. B. Farnham and D. Y. Sogah, Polym. Prepr., Am. Chem. Soc., Div. Polym. Chem., 27, 167 (1986).

3. D. Y. Sogah and W. B. Farnham in "Organosilicon and Bioorganosilicon Chemistry," H. Sakurai, Ed., Wiley, New York, N.Y., 1986, p 219.

4. R. P. Quirk and G. P. Bidinger, Polym. Bull., 22, 63 (1989).

5. R. P. Quirk and J. Ren, Macromolecules, 25, 6612 (1992).

6. A. H. E. Müller, L. Lochman, and J. Trekoval, Macromol. Chem., 187, 1473 (1986).

7. M. A. Müller and M. Stickler, Makromol. Chem., Rapid Commun., 7, 575 (1986).

8. T. Nakano and D. Y. Sogah, J. Am. Chem. Soc., 117, 534 (1995).

9. K. G. Bannerjee and T. E. Hogen-Esch, Macromolecules, 26, 926 (1993).

10. H. Yuki, K. Hatada, T. Ninomi, and Y. Kikuchi, Polym. J., 1, 36 (1970).

11. K. Ute, T. Tarao, and K. Hatada, Polym. J., 29, 957 (1997).

12. K. Ute, T. Tarao, S. Nakao, and T. Kitayama, Polymer, 44, 7869 (2003).

13. a) R. Zhuang and A. H. E. Müller, Macromolecules, 28, 8035 (1995). 
b) R. Zhuang and A. H. E. Müller, Macromolecules, 28, 8043 (1995).

14. K. Ute, T. Tarao, S. Hongo, H. Ohnuma, K. Hatada, and T. Kitayama, Polym. J., 31, 177 (1999).

15. 1-Methoxy-1-(tert-butyldimethylsiloxy)-2-methyl-1-propene, the ketene silyl acetal with the same parent group as (1) and (2), was found far less reactive in the GTP. Thus the acetal (3) $\left(\mathrm{R}_{1}=\mathrm{H}\right)$ was used in the present work.

16. H. Vorbrügen, K. Krolikiewicz, and B. Bennua, Chem. Ber, 114, 1234 (1981).

17. H. C. Marsmann and H. G. Horn, Z. Naturforsch. B, 27, 1448 (1972).

18. M. Schmeißer, P. Sartori, and B. Lippsmeier, Chem. Ber, 103, 868 (1970).

19. H. W. Roesky and H. H. Giere, Z. Naturforsch. B, 25, 773 (1970).

20. G. Simchen and W. Kober, Synthesis, 259 (1976).
21. H. Emde and G. Simchen, Synthesis, 867 (1977).

22. M. R. Detty and M. D. Seidler, J. Org. Chem., 46, 1283 (1981).

23. R. J. Ogg, P. B. Kingsley, and J. S. Taylor, J. Magn. Reson., Ser. B, 104, 1 (1994).

24. W. J. Brittain and I. B. Dicker, Polym. Int., 30, 101 (1993).

25. W. J. Brittain and I. B. Dicker, Makromol. Chem., Macromol. Symp., 67, 373 (1993).

26. In the previous work, we found that, in the polymerizations of methyl crotonate by ketene silyl acetal 2, type of cocatalyst, $\left(\mathrm{CH}_{3}\right)_{3} \mathrm{SiI}$ or $\left(\mathrm{C}_{2} \mathrm{H}_{5}\right)_{3} \mathrm{SiI}$, did not affect the stereostructure of the polymers obtained, suggesting the silyl group in the ketene silyl acetal has the prime importance in the stereoregulation.

27. K. Ute, T. Asada, Y. Nabeshima, and K. Hatada, Macromolecules, 26, 7086 (1993). 